\title{
Estandarización de un protocolo para la combinación de técnicas neurohistológicas en cortes obtenidos con vibrátomo
}

\author{
Lukas Tamayo-Orrego, Orlando Torres-Fernández \\ Laboratorio de Microscopía, Grupo de Morfología Celular, Subdirección de Investigación, \\ Instituto Nacional de Salud, Bogotá D.C., Colombia
}

Introducción. El estudio histológico del sistema nervioso ha requerido del uso de técnicas especiales. Esto se debe a que no existen métodos que permitan visualizar, simultáneamente, todos los constituyentes celulares del tejido nervioso.

Objetivos. Adaptar un protocolo para llevar a cabo un método de coloración del tejido nervioso, previamente conocido pero poco utilizado hasta ahora, debido a las dificultades que presenta el procedimiento original.

Materiales y métodos. Se trabajó con cortes de encéfalo y médula espinal de $4 \mathrm{~mm}$ de espesor, extraídas de ratones adultos previamente fijados mediante perfusión intracardiaca con paraformaldehído al $4 \%$. En un vibrátomo se obtuvieron cortes de 15 a $25 \mu \mathrm{m}$ de espesor. Éstos se montaron sobre láminas portaobjeto preparadas con gelatina como adhesivo. Las preparaciones se sometieron al protocolo de coloración Luxol Fast Blue-PAS-Hematoxylin (LPH) y, su combinación, con un método de tinción argéntica (LPH-Holmes).

Resultados. La técnica LPH permitió obtener una excelente diferenciación de la sustancia gris y la sustancia blanca en todas las regiones del sistema nervioso. En una vista panorámica, la sustancia gris se observa de color rosado, mientras que las fibras y tractos nerviosos con mielina se apreciaron de color azul claro. La combinación LPH-Holmes conservó las características de la tinción, pero mejoró ostensiblemente la demarcación de los axones y tractos.

Conclusiones. Se estandarizó un protocolo para llevar a cabo la tinción LPH y su combinación LPHHolmes en cortes obtenidos con un vibrátomo. Éste es más corto, menos dispendioso y menos costoso que el original y, además, preserva mejor la integridad del tejido nervioso.

Palabras clave: neuronas, neuroanatomía, sistema nervioso, tejido nervioso, técnicas histológicas, vaina de mielina.

Protocol for the combination of neurohistological techniques on vibratome obtained sections

Introduction. The histological study of the nervous system requires the use of special techniques. Currently, no methods are available to visualize simultaneously all the cellular constituents of nervous tissue.

Objectives. A protocol was adapted for staining nervous tissue by modification of a formerly difficult procedure.

Materials and methods. Slices of brain and spinal cord, $4 \mathrm{~mm}$ thick, were taken from adult mice, previously fixed by intracardiac perfusion with $4 \%$ paraformaldehyde. Vibratome sections were obtained with thickness of 15-25 $\mu \mathrm{m}$. These were mounted on glass slides prepared with gelatin as an adhesive. The preparations were subjected to staining protocol Luxol Fast Blue-PAS-hematoxylin (LPH) combined with silver staining method (LPH-Holmes).

Results. LPH technique yielded an excellent differentiation of gray and white matter in all regions of the nervous system. A panoramic view of the gray matter was colored pink in contrast to the myelinated nerve fibers and tracts which were light blue. The combination LPH-Holmes retained the staining characteristics but significantly improved the demarcation of axons and tracts.

Conclusions. A protocol was standardized for the LPH and LPH-Holmes nervous tissue stains applied in combination to tissue slices obtained with a vibratome. The method was shorter, less wasteful and less expensive than the original and also better preserved the integrity of nervous tissue.

Key words: neurons, neuroanatomy, nervous system, nerve tissue, histological techniques, myelin sheath. 
Desde sus orígenes, el estudio histológico del sistema nervioso ha requerido el uso de técnicas especiales, además de los procedimientos rutinarios (1). Esto se debe a que no existen métodos que permitan visualizar, simultáneamente, todos los constituyentes celulares del tejido nervioso: cuerpos neuronales, dendritas y axones, así como los diferentes tipos de células de la glía. El estudio detallado de cada uno de ellos ha conducido al desarrollo de procedimientos especiales (2-4). Entre éstos, se encuentran los métodos de plata reducida, las tinciones para mielina, las impregnaciones argénticas y las técnicas citoquímicas e inmunohistoquímicas. Algunos de estos métodos no hacen parte de los protocolos rutinarios en los laboratorios de diagnóstico neurohistopatológico, pero sí se utilizan para la investigación en neurociencias (5-8).

En 1987, Goto estandarizó un procedimiento que reunía varios tipos de técnicas histológicas para discriminar diversos componentes del tejido nervioso (9). La tinción más importante del protocolo es la coloración Luxol Fast Blue-PASHematoxilin (LPH), una forma mejorada de la tradicional técnica de Klüver-Barrera (10) que, además de mostrar las estructuras vasculares y meníngeas, permite diferenciar la sustancia gris, rica en células, de la sustancia blanca, compuesta principalmente por axones y mielina. El uso del protocolo estandarizado por Goto no se extendió, probablemente, porque fue diseñado para tejido incluido en celoidina. Este medio de inclusión fue muy utilizado en la primera mitad del siglo $X X$, pero ha sido abandonado casi totalmente por ser un procedimiento largo y dispendioso y porque requiere de micrótomos especiales (3). En una breve revisión en Pubmed, se encontraron tan sólo una docena de referencias de artículos en los cuales se menciona el uso de la técnica LPH en estudios neurohistológicos, todos ellos publicados por su autor original.

Por el contrario, en las últimas dos décadas se ha incrementado el uso de vibrátomos (micrótomos de vibración) en los laboratorios de neurociencias. Estos equipos permiten obtener

\footnotetext{
Correspondencia:

Orlando Torres-Fernández, Laboratorio de Microscopía, Grupo de Morfología Celular, Instituto Nacional de Salud, Avenida Calle 26 N ${ }^{\circ}$ 51-20, Bogotá, D.C., Colombia.

Teléfono: (571) 220 7700, extensión 1262

otorresf@ins.gov.co
}

Recibido: 02/12/10; aceptado:30/03/11 cortes relativamente gruesos (más de $10 \mu \mathrm{m}$ de espesor), como los que antes se realizaban en celoidina, sin tener que procesar el tejido en medios de inclusión; por lo tanto, conservan muy bien la morfología y antigenicidad tisular, características importantes para llevar a cabo con éxito estudios con técnicas inmunohistoquímicas y de microscopía electrónica (11-15). Igualmente, el uso del vibrátomo ha permitido la adaptación y simplificación de protocolos neurohistológicos que eran ya poco utilizados, como la técnica de GolgiCox (16).

Con estos antecedentes, se presenta un protocolo estandarizado en nuestro laboratorio que permite realizar y combinar varias coloraciones neurohistológicas en cortes de vibrátomo, entre las cuales se encuentra la coloración LPH (9) y la impregnación argéntica de Holmes (17). Además, se procesaron algunos bloques de tejido mediante la técnica convencional de inclusión en parafina (3).

\section{Materiales y métodos}

\section{Preparación del tejido nervioso}

Se trabajó con cortes de encéfalo y médula espinal de $4 \mathrm{~mm}$ de espesor, extraídas de ratones adultos (28 a 30 días de edad). Este material biológico correspondía al archivo de muestras del laboratorio conservadas en solución tamponada de paraformaldehído al $4 \%\left(\mathrm{a}^{\circ} \mathrm{C}\right)$, correspondientes a trabajos anteriores llevados a cabo por el grupo y que contaban con el aval del Comité de Ética del Instituto Nacional de Salud $(5,8,12,13)$.

Los cortes se montaron en un micrótomo de vibración (Vibratome $\AA$ ) y se obtuvieron cortes de 15, 25 y $50 \mu \mathrm{m}$ de espesor. Los cortes se extendieron, con ayuda de un pincel, sobre láminas portaobjeto cubiertas con gelatina al $1 \%$ y se dejaron secar al ambiente, para que se adhirieran bien antes de rehidratarlos e iniciar las coloraciones.

Las láminas portaobjeto se habían preparado previamente de la siguiente manera: se lavaron profusamente con jabón y agua bidestilada, se enjuagaron en etanol absoluto y se dejaron secar al ambiente. A continuación, se sumergieron brevemente en la solución de gelatina al $1 \%$ y se dejaron secar al ambiente. La gelatina se preparó así: se disolvieron 2,5 g de gelatina en polvo (Merck) en $250 \mathrm{ml}$ de agua caliente. Se adicionaron $0,25 \mathrm{~g}$ de sulfato de cromo y potasio y $0,25 \mathrm{~g}$ de azida de sodio. 


\section{Preparación de colorantes}

Luxol Fast Blue al 0,1\%: se disolvió 0,1 g de Luxol Fast Blue-MBSN (Sigma Solvent Blue 38) en $100 \mathrm{ml}$ de etanol al $95 \%$ y se filtró antes de usar $(9,18)$.

Reactivo de Schiff: se preparó de forma tradicional con fucsina básica. Para cortes de tejido incluido en parafina, es recomendable utilizar pararosanilina (3).

Hematoxilina de Papamiltiades: se disolvió $1 \mathrm{~g}$ de hematoxilina en $12,5 \mathrm{ml}$ de etanol absoluto. Por separado, se agregaron $25 \mathrm{~g}$ de sulfato de potasio y aluminio $\left[\mathrm{KAl}\left(\mathrm{SO}_{4}\right)_{2}\right]$ a $250 \mathrm{ml}$ de agua destilada; el reactivo se disolvió a medida que se calentaba la solución. Se mezclaron las dos soluciones y la solución resultante se llevó rápidamente hasta ebullición. Luego, se retiró del calor y se le agregaron lentamente $0,625 \mathrm{~g}$ de óxido de mercurio $(\mathrm{HgO})$ bajo campana de extracción. Cuando la hematoxilina tomó un color púrpura, se dejó enfriar la solución; luego se conservó a $4{ }^{\circ} \mathrm{C}$ hasta el momento de su utilización (18).

Solución de impregnación de Holmes:se prepararon $55 \mathrm{ml}$ de ácido bórico al 1,24 \% y se mezclaron con $45 \mathrm{ml}$ de bórax al $1 \%$. Luego, se adicionaron 394 $\mathrm{ml}$ de agua destilada. A continuación se agregó 1 $\mathrm{ml}$ de nitrato de plata $\left(\mathrm{AgNO}_{3}\right)$ al $1 \%$ y $5 \mathrm{ml}$ de piridina al $10 \%$. Se mezcló bien la solución y se conservó a $4{ }^{\circ} \mathrm{C}$; esta solución se puede reutilizar varias veces, pero la calidad de la impregnación disminuye con cada uso $(17,18)$.

Solución reductora de Holmes: se agregaron $1 \mathrm{~g}$ de hidroquinona y $10 \mathrm{~g}$ de sulfito de sodio $\left(\mathrm{Na}_{2} \mathrm{SO}_{3}\right)$ a $100 \mathrm{ml}$ de agua destilada. Se disolvió bien y se conservó la solución a $4^{\circ} \mathrm{C}$; ésta puede utilizarse varias veces $(17,18)$.

Se tomó como punto de partida la coloración LPH según Goto (9), pero se modificaron los tiempos de coloración y algunos de los colorantes. Esta tinción fue combinada satisfactoriamente con la impregnación argéntica de Holmes (17), uno de los métodos de plata reducida más utilizado. A continuación, se describen los protocolos que se siguieron para desarrollar las tinciones.

\section{Protocolo para la tinción LPH}

Las preparaciones histológicas de tejido nervioso recibieron la siguiente serie de tratamientos:

1. Se sumergieron en agua corriente para hidratar los cortes previamente adheridos a las láminas con gelatina.
2. Se pasaron brevemente por etanol al $70 \%$ y luego al $95 \%$.

3. Se colocaron en Luxol Fast Blue al 0,1\% durante toda la noche, en un vaso Coplin bien sellado, a $60^{\circ} \mathrm{C}$.

4. Se enjuagaron brevemente en etanol al $95 \%$ y luego al 70 \%; a continuación se sumergieron en agua destilada.

5. Para diferenciar la tinción, se transfirieron las preparaciones a una solución de carbonato de litio $\left(\mathrm{LiCO}_{3}\right)$ al 0,05\%, por un minuto, luego a etanol al $70 \%$ por el mismo tiempo y se lavaron en agua destilada. Este paso se debe repetir las veces necesarias hasta obtener la diferenciación requerida (intensificación del tono azul de la coloración en la sustancia blanca y pérdida de la tinción azul en la sustancia gris). Para cortes de material incluido en parafina, fueron suficientes uno o dos ciclos.

6. Se lavaron las láminas en agua destilada.

7. Las preparaciones se trataron con ácido peryódico $\left(\mathrm{H}_{5} \mathrm{IO}_{6}\right)$ al $0,5 \%$ durante cinco minutos (oxidación).

8. Se lavaron varias veces en agua destilada.

9. Se sumergieron las preparaciones en el reactivo de Schiff durante 10 a 15 minutos.

10. Luego se lavaron en agua corriente por otros 15 minutos (la sustancia gris toma un color rosado).

11. Se enjuagaron brevemente con agua destilada.

12. Se colorearon con hematoxilina de Papamiltiades (o de Carazzi) por 2 a 3 minutos. Para los tejidos incluidos en parafina, se necesitaron 4 a 5 minutos.

\section{Protocolo para la coloración LPH-Holmes}

1. Se inició con los primeros seis pasos de la coloración LPH.

2. Luego se cubrieron los cortes con gotas de nitrato de plata al $20 \%$, por una hora, en la oscuridad.

3. Se lavaron las preparaciones en agua destilada: tres cambios por 10 minutos cada uno.

4. Se sumergieron las láminas en la solución de impregnación de Holmes durante 12 horas.

5. Luego, sin lavar, se sumergieron en la solución reductora de Holmes por 2 a 4 minutos. Los cortes tomaron un color parduzco. 
6. Se cubrieron los cortes con gotas de cloruro de oro al $0,2 \%$, durante tres minutos.

7. Las preparaciones se lavaron con agua inmediatamente después de que los cortes se tornaron grises.

8. Las láminas se sumergieron en ácido oxálico al $2 \%$ por 1 a 4 minutos y se enjuagaron en agua destilada.

9. Luego se trataron con tiosulfato de sodio al $5 \%$ por tres minutos y se lavaron en agua destilada por 10 minutos.

10.Se continuó con la coloración LPH desde el paso 8; la duración del tratamiento del paso 9 (reactivo de Schiff) se reduce a cinco minutos. Se puede omitir el paso 12 si se quiere mantener el énfasis en la coloración de los axones. Además, se puede llevar a cabo la contracoloración con violeta de cresilo.

También, se puede hacer únicamente la impregnación de Holmes (pasos 2 a 10) y, si se desea, contracolorear con hematoxilina o violeta de cresilo. Finalmente, después de terminar cada coloración, se realiza la deshidratación en concentraciones ascendentes de etanol y se aclara en xilol, como de rutina, para finalmente montar con una resina.

Se tomaron fotografías de las preparaciones histológicas con una cámara Evolution VF de MediaCybernetics ${ }^{\circledR}$ acoplada a un microscopio Zeiss Axiophot.

\section{Resultados}

\section{Coloración LPH}

La técnica permitió obtener una excelente diferenciación de la sustancia gris y la sustancia blanca en todas las regiones del sistema nervioso, con gran intensidad y contraste de los colores. En una vista panorámica, la sustancia gris se observa de color rosado mientras que las fibras y tractos nerviosos con mielina se apreciaron de color azul claro (azul turquesa) y, la mayoría de núcleos celulares, de color azul oscuro (figuras 1-3). A mayor aumento se pueden distinguir en detalle los axones mielínicos de los demás componentes del neuropilo (figura 4). En algunas áreas se observaron también depósitos de pigmentos positivos para PAS en células endoteliales y neuronas, y los eritrocitos, de color azul brillante. El tiempo total requerido para completar la coloración fue de tres horas (sin contar la preparación de reactivos).

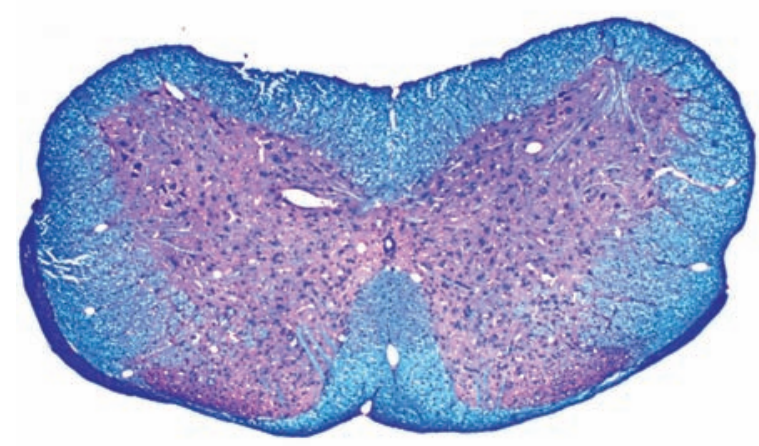

Figura 1. Corte transversal de médula espinal de ratón, a nivel cervical, obtenido con vibrátomo y coloreado con el protocolo $\mathrm{LPH}$. En el centro se observa la sustancia gris (cuerpos neuronales) de color rosado y en forma de mariposa. En la periferia se encuentra la sustancia blanca (tractos de axones con mielina) de color azul turquesa, $5 \mathrm{X}$.

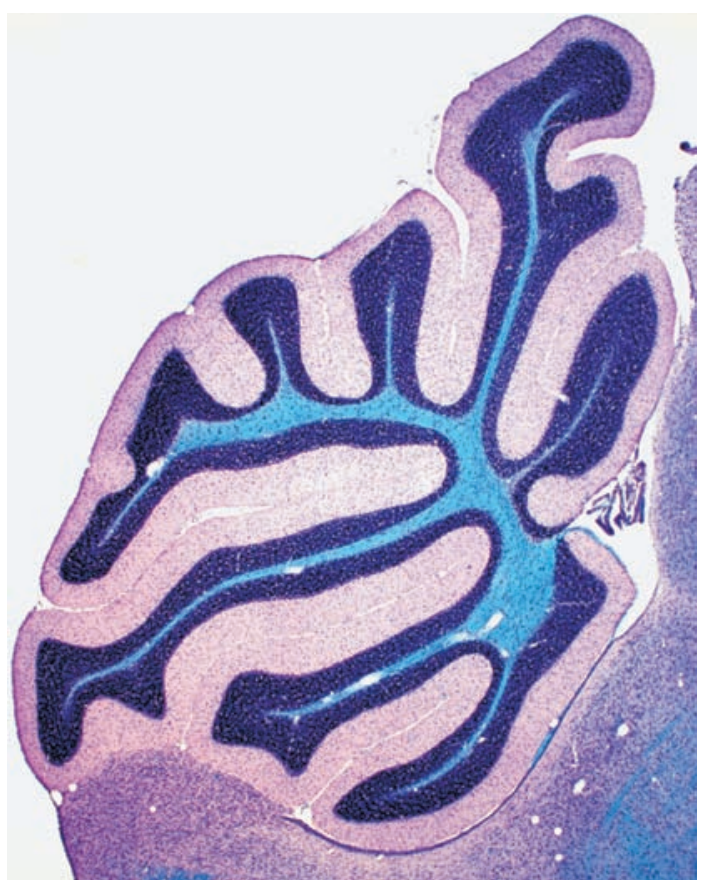

Figura 2. Corte sagital de cerebelo de ratón obtenido con vibrátomo y coloreado con el protocolo LPH. En la corteza cerebelar se observan la capa molecular de color rosado y la capa de células granulares de color azul oscuro. En el centro, la sustancia blanca exhibe un color azul turquesa, 2,5X.

\section{Coloración LPH-Holmes}

Esta coloración mantiene la diferenciación entre la sustancia blanca y la sustancia gris, aunque con algunas diferencias, especialmente por la coloración rojiza de los núcleos (figura 5). La impregnación de los axones fue de excelente calidad en todas las regiones del sistema nervioso; a los axones de mayor calibre, localizados muchos de ellos en el tallo cerebral, se les pudo seguir el recorrido hasta 


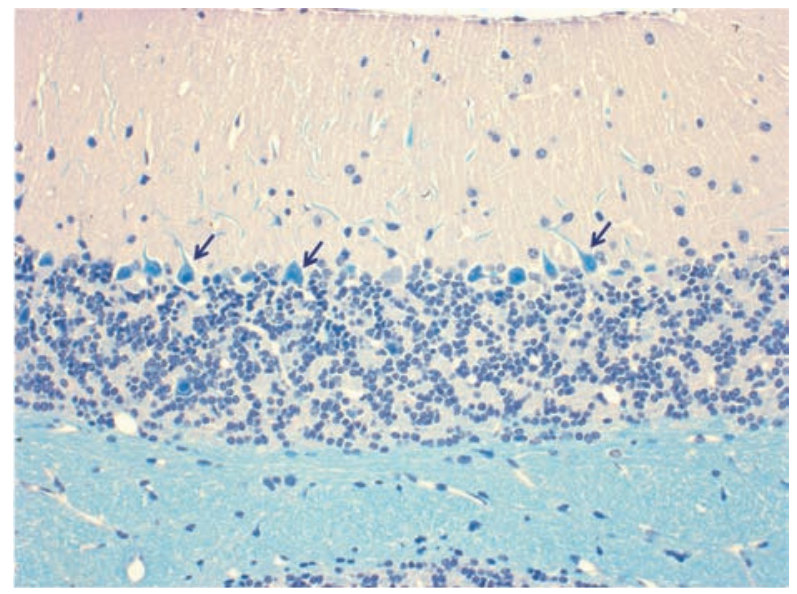

Figura 3. Corte de la corteza del cerebelo, obtenido a partir de tejido incluido en parafina, y coloreado con LPH. Se exhiben, de arriba hacia abajo, las tres capas celulares: molecular (arriba), células de Purkinje (flechas), células granulares (en el centro, de color azul oscuro) y la sustancia blanca subyacente (azul claro). Aquí las células de Purkinje y fragmentos de sus dendritas, dentro de la capa molecular, se observan de color azul, debido a que el tiempo de diferenciación fue muy corto, 20X.

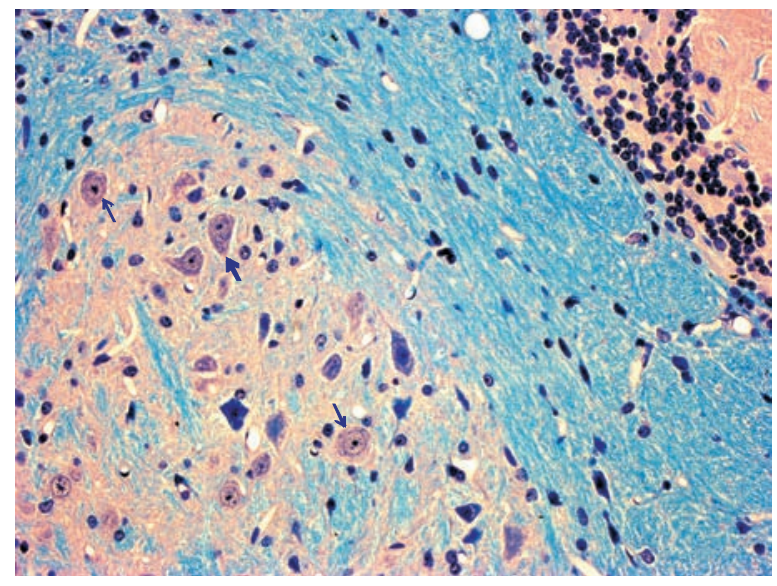

Figura 4. Detalle de un campo de uno de los núcleos profundos del cerebelo (grupo de neuronas). Se observan varios cuerpos neuronales (flechas) rodeados por neuropilo compuesto por sustancia gris rosada (procesos celulares dendríticos) y sustancia blanca teñida de azul (axones mielínicos). Corte de tejido incluido en parafina y coloreado con LPH, 25X.

por cientos de micras gracias al grosor de los cortes (figuras 6 y7). Los axones no se desimpregnaron, por lo menos por un período de un año, aunque las láminas hubieran sido montadas en medio de montaje comercial convencional (fabricación nacional). El tiempo requerido para completar la coloración fue de cuatro horas y treinta minutos.

\section{Observaciones adicionales}

La coloración LPH, así como la combinación LPHHolmes, se obtuvieron satisfactoriamente con cortes

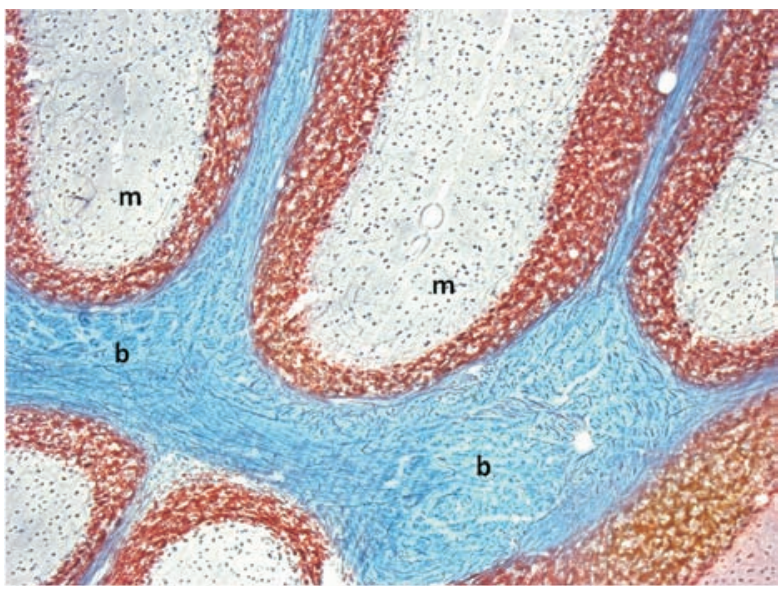

Figura 5. Corteza del cerebelo cortada en vibrátomo y coloreada con la combinación LPH-Holmes. Se conserva el color azul de la sustancia blanca (b). La capa granular toma un color caférojizo. En la capa molecular $(\mathrm{m})$ y dentro de la sustancia blanca son evidentes las fibras de axones, 20X.

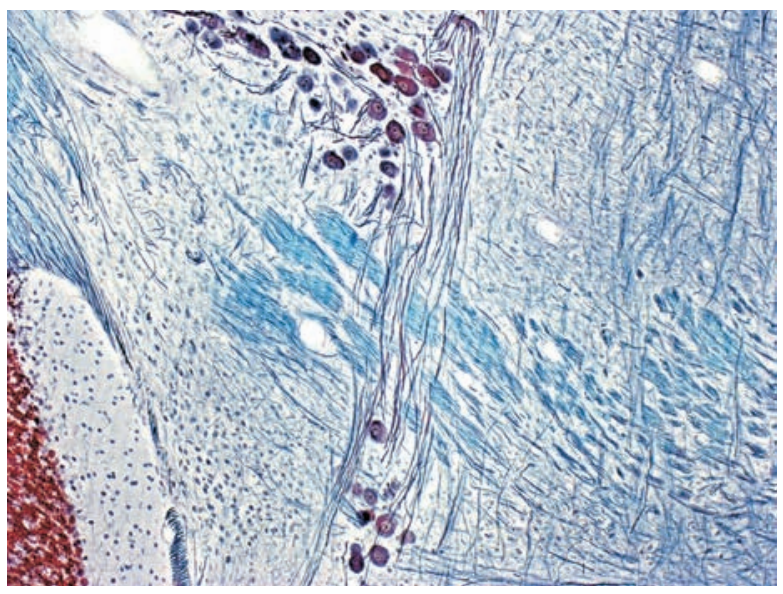

Figura 6. Corte sagital a nivel del tallo cerebral, detrás del cerebelo, coloreado con LPH-Holmes. Esta tinción destaca los tractos de fibras de axones (de color oscuro) que corren en diferentes direcciones. Los cuerpos neuronales presentan una tonalidad rojiza, 20X.

de material incluido en parafina (figuras 3 y 4); en este caso, los resultados fueron mejores con cortes de 8 a $10 \mu \mathrm{m}$ de espesor. Los cortes en parafina permitieron una mejor visualización de la morfología celular interna. El espesor óptimo de los cortes obtenidos en vibrátomo osciló entre 15 y $25 \mu \mathrm{m}$. Los cortes muy gruesos absorbieron demasiado los colorantes y se tornaron muy oscuros. El montaje de los cortes sobre láminas con gelatina como adhesivo, evitó la excesiva reducción de su tamaño durante la deshidratación, a diferencia de lo que ocurrió en un ensayo previo en el que los cortes de vibrátomo se deshidrataron flotando en los reactivos, en los cuales la reducción de 


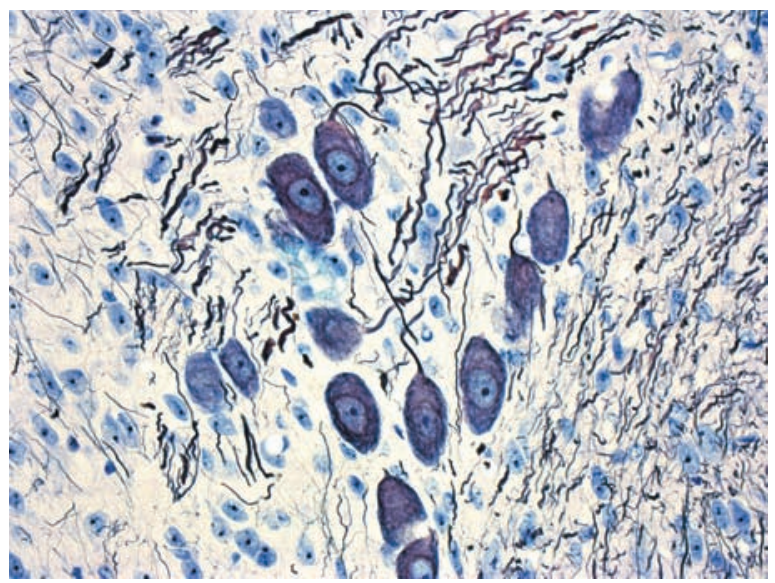

Figura 7. Imagen de un grupo de neuronas dentro del tallo cerebral. Se observa el recorrido inicial de algunos axones desde su respectiva neurona de origen y muchos otros fragmentos de axones impregnados por la tinción argéntica. Coloración LPHHolmes contrastada con violeta de cresilo, 40X.

tamaño alcanzó, aproximadamente, un cincuenta por ciento. Además, sólo unos pocos cortes se desprendieron durante todo el procedimiento de coloración.

\section{Discusión}

Con este trabajo hemos revivido un procedimiento para el estudio neurohistológico, publicado hace más de dos décadas, pero infortunadamente ignorado, tal vez porque algunas etapas del procedimiento son muy dispendiosas y porque el auge de otras técnicas modernas de estudio ha hecho que los técnicos e investigadores dirijan más su atención hacia ellas. Por esta misma razón, se han abandonado otras técnicas neuroanatómicas.

Aquí vale la pena citar las palabras de un científico español reconocido internacionalmente por su aporte en el campo de la neurociencia:

"[...] No son raras las presiones para conceder primacía a determinadas disciplinas de la neurociencia en menoscabo de la neuroanatomía. Estas presiones surgen del desconocimiento de la importancia que tiene en este campo poner todo nuevo hallazgo dentro de un contexto estructura [...]" (19).

Hemos estandarizado un procedimiento que permite llevar a cabo las variantes técnicas publicadas por Goto (9), pero mediante el uso de cortes obtenidos en vibrátomo, en lugar de la inclusión del tejido en celoidina. Nuestro protocolo es más corto, menos dispendioso, menos costoso y preserva mejor la integridad del tejido. También, puede facilitar la combinación de la técnica de
Goto con otras técnicas (inmunohistoquímica, microscopía electrónica, técnica de Golgi, etc.) o con otras tinciones. Así, por ejemplo, hemos podido realizar la coloración LPH con la impregnación de Holmes de forma simultánea. Hasta donde tenemos conocimiento, éste es el primer reporte de la combinación satisfactoria de estas coloraciones. El Luxol Fast Blue hace visible la mielina, el PAS revela pigmentos, la hematoxilina marca los núcleos celulares y la impregnación de Holmes resalta la trayectoria de los axones mielínicos. Por lo tanto, este método sirve para revelar un gran número de elementos neurohistológicos en el mismo corte mediante un protocolo unificado.

Las ventajas de utilizar cortes de vibrátomo, se resumen así:

1) es un equipo muy fácil de manejar; para la obtención de los cortes no se necesita la destreza que se debe adquirir para manejar micrótomos y sus elementos conexos;

2) no se requiere la inclusión del tejido, lo cual reduce tiempo y costos, y se evita someter a los componentes tisulares a temperaturas más altas y al tratamiento con solventes antes de obtener los cortes, y

3) permite visualizar detalles que sólo aparecen en cortes gruesos, por ejemplo, seguir la trayectoria completa de los axones.

Con el fin de obtener imágenes compuestas de estructuras histológicas del sistema nervioso, se han utilizado combinaciones de los métodos de plata reducida con otras coloraciones, como el método de Klüver-Barrera-Bodian o la coloración Luxol Fast Blue-Holmes (18), muy parecida al protocolo que se presenta en este trabajo. No obstante, en el presente protocolo, se ha invertido el orden de la coloración, de tal forma que la impregnación argéntica se ha realizado casi al final, con lo que se mejora la impregnación de los axones. En el método de Goto (9), la coloración LPH fue combinada con la impregnación argéntica de Hirano y Zimmerman (20) para neuronas y axones; éste es un método de plata reducida simplificado y muy efectivo para material incluido en celoidina. Por lo tanto, en nuestro protocolo se escogió la impregnación de Holmes, aunque ésta se conocía sólo para cortes de material incluido en parafina. La tinción de Holmes no produce impregnación de los cuerpos celulares, a excepción del núcleo, hecho que permitió mantener los colores de la tinción $\mathrm{LPH}$. 
Aunque la coloración LPH-Holmes revela buena parte de los componentes del tejido nervioso, es necesario acudir a otros métodos para el estudio de la morfología dendrítica, como la técnica de Golgi o las técnicas de inyección intracelular de colorantes o trazadores neuronales (7). Por otra parte, el estudio específico de los tipos de células gliales y de los productos de degradación de las neuronas, requiere de otras técnicas $(2-4,18)$.

En conclusión, hemos desarrollado un nuevo protocolo para el realizar estudios neurohistológicos en cortes de vibrátomo mediante la modificación del método de Goto (9), haciéndolo más fácil y menos costoso. La técnica se puede utilizar para el estudio neurohistológico básico y podría emplearse de forma complementaria en el estudio de la patogénesis de enfermedades del sistema nervioso.

\section{Agradecimientos}

A los integrantes del Grupo de Patología del Intituto Nacional de Salud, por su colaboración con el procesamiento del tejido nervioso para la obtención de cortes a partir de material incluido en parafina.

\section{Conflictos de interés}

Los autores declaramos no tener conflictos de interés.

\section{Financiación}

Subdirección de Investigación, Instituto Nacional de Salud.

\section{Referencias}

1. Ramón y Cajal S, Tello y Muñoz JF. Elementos de histología normal y técnica micrográfica. Barcelona: Editorial Científico Médica; 1931.

2. Lowe J, Cox G. Neuropathological techniques. En: Bancroft JD, Stevens A, editors. Theory and practice of histological techniques. Edinburgh: Churchill Livingstone; 1990. p. 34378.

3. Garcia del Moral R. Laboratorio de anatomía patológica. Madrid: McGraw-Hill Interamericana; 1993.

4. Haberland C. Clinical Neuropathology; text and color atlas. New York: Demos Medical Publishing; 2007.

5. Torres-Fernández $\mathrm{O}$, Yepes GE, Gómez JH, Pimienta HJ. Efecto de la infección por el virus de la rabia sobre la expresión de parvoalbúmina, calbindina y calretinina en la corteza cerebral de ratones. Biomédica. 2004;24:63-78.

6. Torres-Fernández $\mathrm{O}$, Yepes GE, Gómez JE, Pimienta HJ. Calbindin distribution in cortical and subcortical brain structures of normal and rabies-infected mice. Int J Neurosci. 2005;115:1375-82.

7. Torres-Fernández $\mathbf{O}$. La técnica de impregnación argéntica de Golgi. Conmemoración del centenario del premio nobel de Medicina (1906) compartido por Camillo Golgi y Santiago Ramón y Cajal. Biomédica. 2006;26:498-508.

8. Torres-Fernández $\mathrm{O}$, Yepes GE, Gómez JE. Alteraciones de la morfología dendrítica neuronal en la corteza cerebral de ratones infectados con rabia: un estudio con la técnica de Golgi. Biomédica. 2007;27:605-13.

9. Goto N. Discriminative staining methods for the nervous system: Luxol fast blue-periodic acid-Schiff-hematoxylin triple stain and subsidiary staining methods. Stain Technol. 1987;62:305-15.

10. Klüver H, Barrera $\mathbf{E}$. A method for the combined staining of cells and fibers in the nervous system. J Neuropathol Exp Neurol. 1953;12:400-3.

11. Castellanos JE, Guayacán OL, Castañeda DR, Hurtado H. Uso de una técnica de inmunoperoxidasa para la detección de virus de rabia en cortes gruesos de cerebro. Biomédica. 1998;18:141-6.

12. Rengifo AC, Torres-Fernández $\mathrm{O}$. Disminución del número de neuronas que expresan GABA en la corteza cerebral de ratones infectados por rabia. Biomédica. 2007;27:548-58.

13. Lamprea $\mathbf{N}$, Torres-Fernández $\mathbf{O}$. Evaluación inmunohistoquímica de la expresión de calbindina en el cerebro de ratones en diferentes tiempos después de la inoculación con el virus de la rabia. Colom Med. 2008;39(Suppl.3):713.

14. Lamprea NP, Ortega LM, Santamaría G, Sarmiento L, Torres-Fernández 0 . Elaboración y evaluación de un antisuero para la detección inmunohistoquímica del virus de la rabia en tejido cerebral fijado en aldehídos. Biomédica. 2010;30:146-51.

15. Schikorski T. Pre-embedding immunogold localization of antigens in mammalian brain slices. Methods Mol Biol. 2010;657:133-44.

16. Gibb R, Kolb B. A method for vibratome sectioning of Golgi-Cox stained whole rat brain. J Neurosci Methods. 1998;79:1-4.

17. Holmes W. Silver staining of nerve axons in paraffin sections. Anat Rec. 1943;86:157-87.

18. McManus JFA, Mowry RW. Staining methods. Histologic and histochemical. New York: Paul Hoeber Inc.; 1960.

19. Fairén A, Smith-Fernández A, DeDiego I. Organización sináptica de neuronas morfológicamente identificadas: el método de Golgi en microscopía electrónica. En: Armengol JA, Miñano FJ, editores. Bases experimentales para el estudio del sistema nervioso. Sevilla: Secretariado de Publicaciones de la Universidad de Sevilla; 1996. p. 17-56.

20. Hirano A, Zimmerman HM. Silver impregnation of nerve cells and fibers in celloidin sections. Arch Neurol. 1962;6: 114-22. 